\title{
Wear evaluation of elements of V-belt transmission with the application of optical microscope
}

\author{
Piotr Krawiec ${ }^{1, *}$, Konrad Waluś ${ }^{1}$ Lukasz Warguła ${ }^{1}$, Jarosław Adamiec ${ }^{1}$ \\ ${ }^{1}$ Poznań University of Technology, Chair of Basics of MachineDesign, Piotrowo 3 60-965 Poznań, \\ Poland
}

\begin{abstract}
The paper presents the analysis of reasons, form and wear of elements of V-belt transmission. Syndromes of loss of driving properties for chosen wheels and V-belts are specified. Methodology of failure evaluation of wheels and V-belts with the application of optical microscope is proposed. The applied measuring set allows for universal analysis of the measurement results. Operation principle of this device and its measuring and analysing abilities are shown. Failures of chosen V-belts and the influence of these failures on accuracy of kinematic features of chosen driving units are evaluated.
\end{abstract}

Keywords: V- belts, belt wear evaluation, optical measurements

\section{Introduction}

One of the first described applications of a rod was constructing a universal machine [1]. It was a basis to construct many other machines in Egyptian times i.e. first versions of turning lathe, transporting machines, etc. The beginning of using V-belts dates back to 1917 when John Gates used them in a car powertrain (fig. 1).

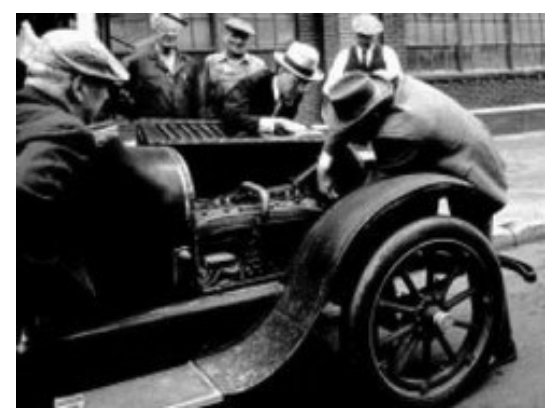

Fig. 1. The car in which V-belt was used for the first time [2]

\footnotetext{
*Corresponding author: piotr.krawiec@put.poznan.pl

Reviewers: Andrej Czán, Juraj Gerlici
} 
Due to their properties and low production costs V-belts and multi-groove belts are widely used in many branches of industry. Their properties were also a starting point for development research conducted by research centers and belts producers. There are a few areas of research of V-belts and multi-groove belts such as: material, construction, production technology [3]. The issues concerning the designing of integrated V-belts are presented in articles [4-5]. The issues concerning the evaluation of properties of V-belts and multi-groove belts are presented in articles [6-9]. This article tries to present the evaluation of belt transmission used in alternator drive of engine of VW Transporter T4 1.9D. Multigroove belts, poly- $\mathrm{V}$ belt pulleys and belt tensioners. The evaluation of wear of belts, tensioners' pulleys was done with the use of optical microscope Bresser BIOLUX ICD BINO 80x LED with camera CMOS 2 MP (fig. 2).

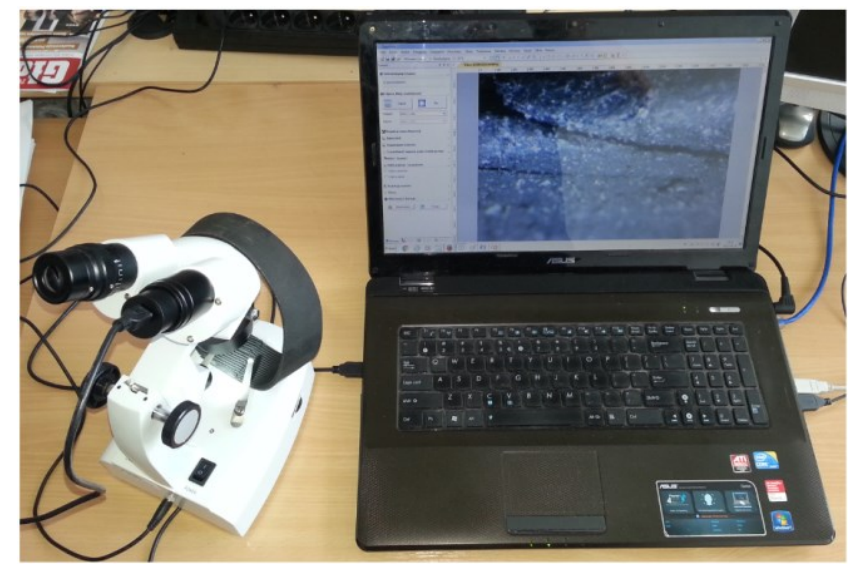

Fig. 2. Optical microscope with the measurement set

\section{Typical causes of V-belts and Multi-groove belts failure}

The most common failures of V-belts and multi-groove belts are:

- Cracking of ribs. On the working surface of belt transversal cracks are visible, alongside one or more ribs (fig. 3). This damage is probably caused by the influence of too high or too low temperatures. Other reason of such failure may be the interaction between the belt and pulley. It is especially important when the pulley diameter is small. If the interaction is incorrect it may cause tensions which lead to cracks. The cracks appear on the top of the rib and then deepen reaching down to the cord.
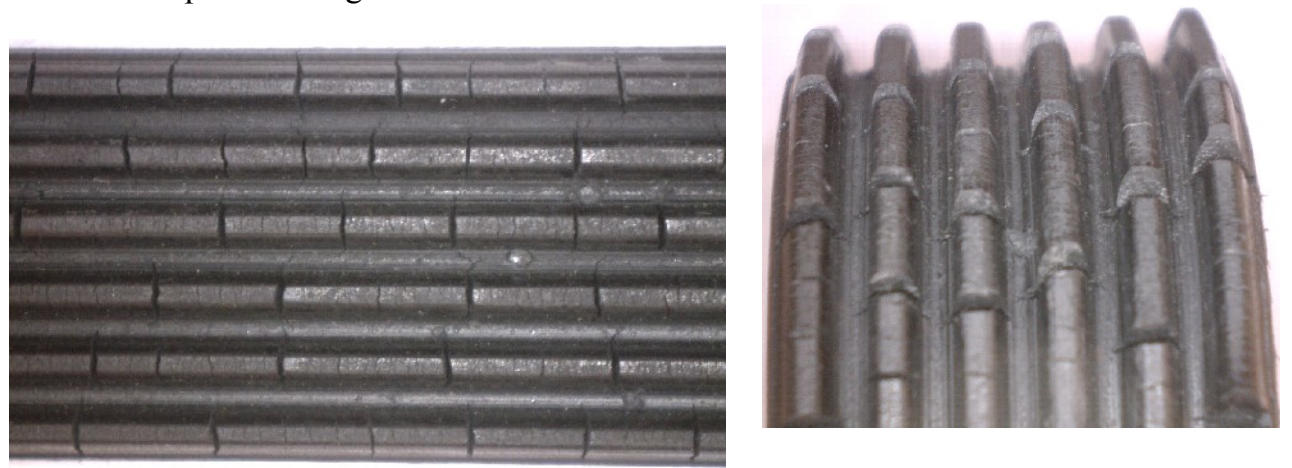

Fig. 3. Multi-groove belt transversal cracks 
- Belt rubber flaking. When rubber flakes (fig. 4) then the belt may break immediately. Such state of the belt may be the result of many cracks cumulating in one place which are parallel to the cord strand. Such state of belt is caused by high temperature, the duration of using the belt and belt tensions.

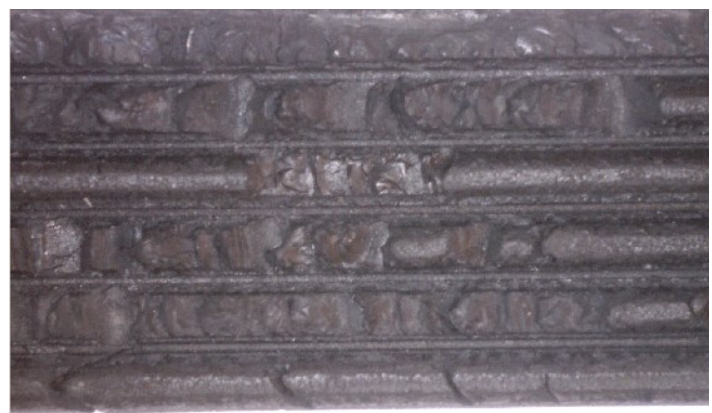

Fig. 4. Rubber flaking in multi-grove belt

- The phenomenon of peeling. Peeling occurs (fig. 5) when the material of the belt is rubbed off the tops of the ribs and accumulates in its grooves. One of the reasons of such situation may be the improper tension of the belt, assembly mistakes or the wear of pulleys. This phenomenon is common for the belt drives of engines propelled by petrol or diesel oil.

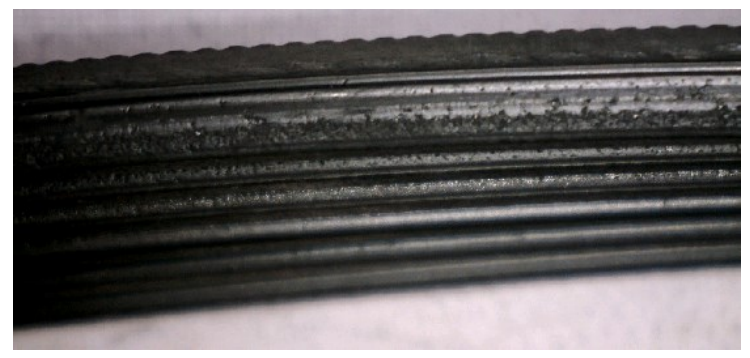

Fig. 5. Peeling phenomenon on multi-groove Belt

- Friction wear. The symptom of friction wear (fig. 6) is a shinny outer surface of the belt. If there is a severe wear of the belt then on its surface a piece of fabric may be visible. This state of wear may be caused by a direct interaction of the belt with an object on its way such as a flange or a screw. Other reason of appearing the friction wear may be the incorrect tension of the belt.

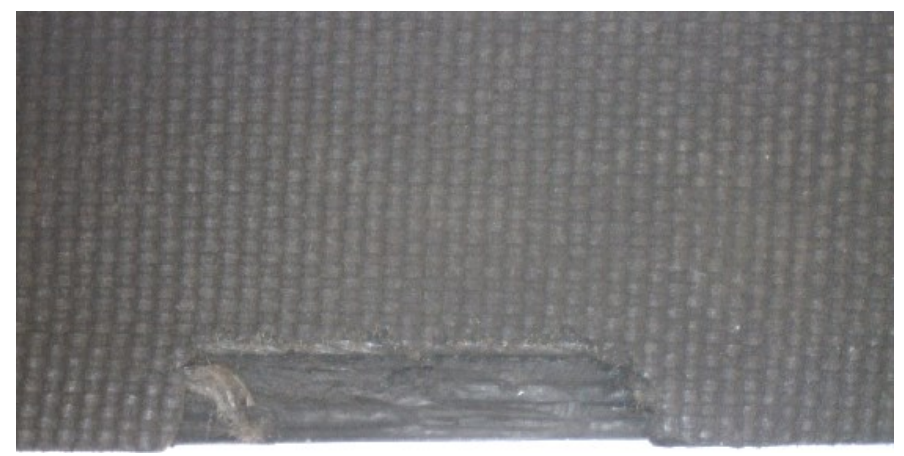

Fig. 6. The friction wear of multi-groove belt 
- The damage of the external belt ribs. The symptoms of such state of belt (fig. 7) appear on its sidewalls. The flat surface of the tie becomes shinny or in the most extreme cases the cord on the sidewalls is ragged. The outermost belt ribs may be rubbed off or torn off. The symptom of such failure may be the noise generated by the transmission. Such a result may be caused by the misalignment of belt pulleys.

The other symptom of such failure is bending or twisting of the belt Chile transmission works.

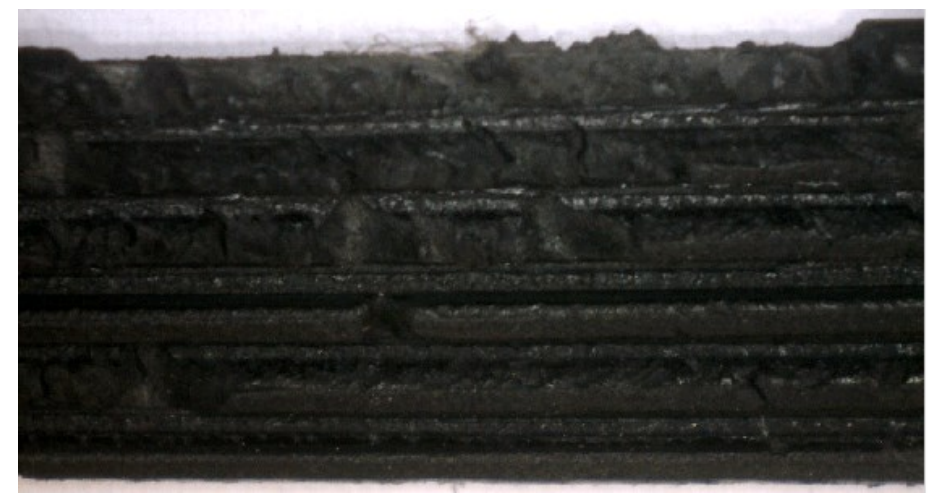

Fig. 7. The damage of the external belt ribs

- The uneven wear of the belt ribs. This kind of wear (fig. 8) is indicated by the damage of the sides of the tie, usually in a form of broken cord or ragged belt ribs. Other indicator of this state of belt is a rumbling or scraping sound in the transmission. The cause of this form of damage may be a foreign matter i.e. a small stone on the pulley. If nothing is done when these symptoms occur then it may result in the uneven wear of the belt, cutting the material of the belt ribs to the cord and eventually lead to its breaking.

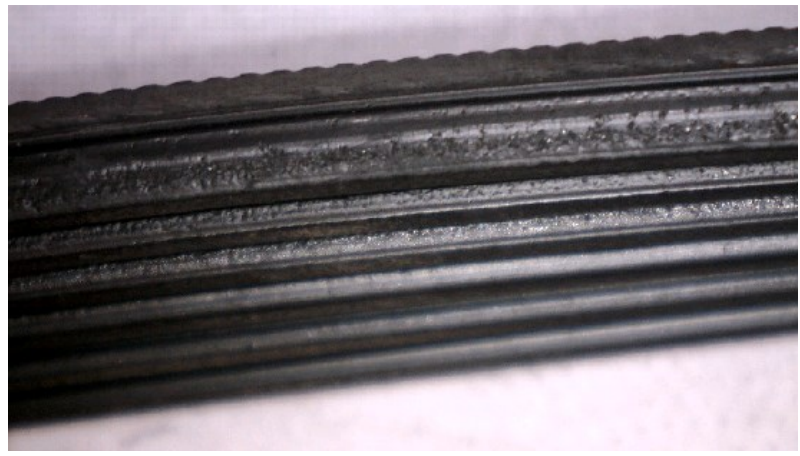

Fig. 8. The uneven wear of the belt ribs

- The influence of contaminations. When on the outer ( smooth) surface appear small punctures or swellings ( fig. 9) and what is more, the fabric around the holes is ragged it may suggests that some contaminations penetrate into the belt. The cause of this form of damage is most often the situation when small stones, sand or gravel penetrate into the belt grooves and pulley grooves. Poly - V belts are produced with different shapes of belt ribs, some of them have sharp tops, others rounded and another ones cut off, as a result the interaction with pulleys differs so the specks of metal are the effect of the pulley rubbing off. 


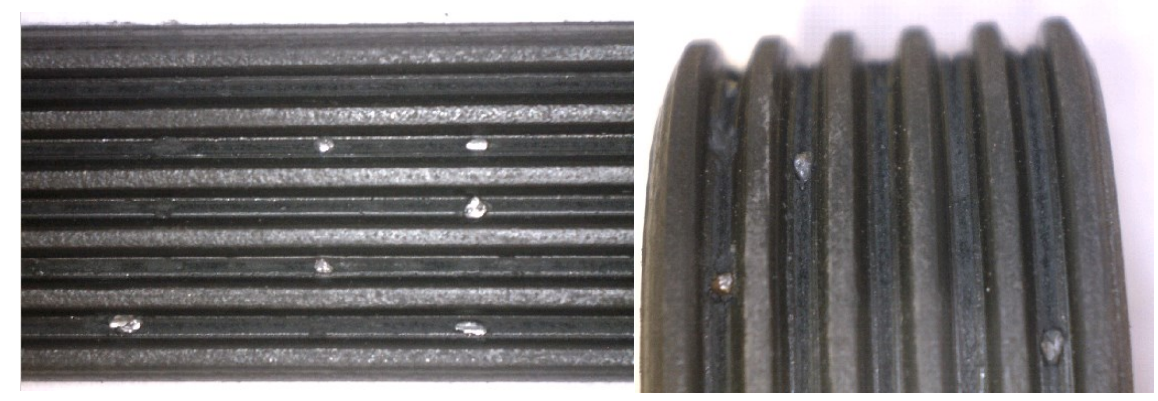

Fig. 9. The influence of contaminations on poly-v belt

- The band separation. This problem occurs when the outmost belt ribs start separating from the rest of the material (fig. 10). When this process lasts longer then the whole rib separates and causes the damage to the fabric and another belt ribs. The reason of such state of the belt is the improper assembly of the transmission. Due to the improper assembly one or more belt ribs is beyond the groove on the pulley what causes lack of corelation of belt sidewalls that lowers significantly the duration of proper transmission work.

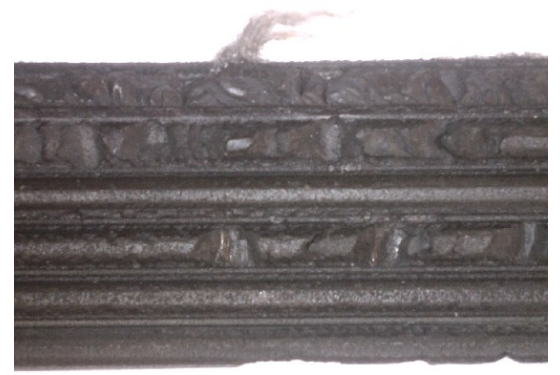

Fig. 10. The band separation

- Contamination by fluids. The surface of the belt is flaking, sticky or swollen (fig. 11). This state of belt may be caused by oil, grease or chemical substances. These substances weaken significantly the internal structure of the belt, influencing its stiffness. The belt starts slipping on the surfaces of the pulleys. Inseparable symptom of this state is the increase of the belt temperature.

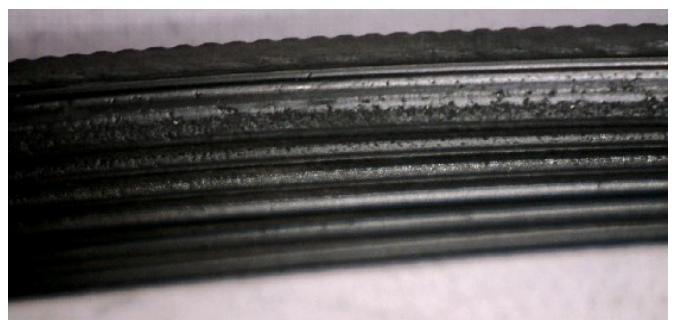

Fig. 11. Fluid contamination in poly-v belts

- Transversal cracking of the belt. This state of belt may be caused by a few reasons. One of them is thrusting of a foreign matter and as a result cutting a piece of belt including the cord. The second reason may be using too much strength when assembling the belt. Another reason for cracking the belt may be a sudden change of the transmission load caused by a blocked pulley. 
- Excessive noise. If the assembly is improper and the pulleys are misaligned then the excess ive noise may occur. The noisiness of belt transmission with poly-v belt may also occur when the belt is very wide. In order to lower the noise level of transmission the belt may be cut into two pieces decreasing its width or use two poly-v belts that work parallel.

\section{The damage of poly-v belt pulleys}

Groove pulleys are widely use in the production of the means of transport. Cars used nowadays have belt transmissions used i.e. to drive the alternator, power steering and air conditioning compressor. As the cars have better performances (speed, torque) it causes vibrations and increases the noise level in the transmission. The natural solutions to this problem becomes applying in the car construction both silencers and transmission which working principle limits the negative effects. The reasons for belt pulley failure (fig. 12) may be: the assembly of the new pulley with the use of old or inappropriate screws as well as assembly mistakes such as incorrect torque while tightening the screws.

The symptoms of wear of multi-groove belt pulleys may be:

- loud work of the poly-v belt,

- slipping of the poly-v belt,

- rust on the outer part of the pulley,

- the increase in the level of vibrations,

- the deformation of the pulley grooves, cracks,

- rubbing of the parts of belt.

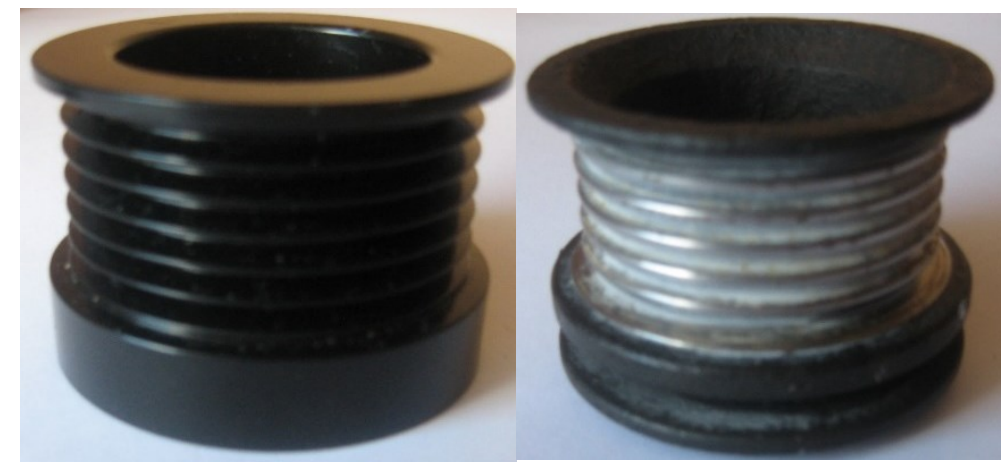

Fig. 12. New pulley and pulley exploited for about $250000 \mathrm{~km}$

\section{The failures of multi-groove pulley tensioners}

The task of multi-groove pulley tensioners is to avoid excessive slippage, decrease the level of vibrations and noise, as well as proper tension of the belt in the drive. 


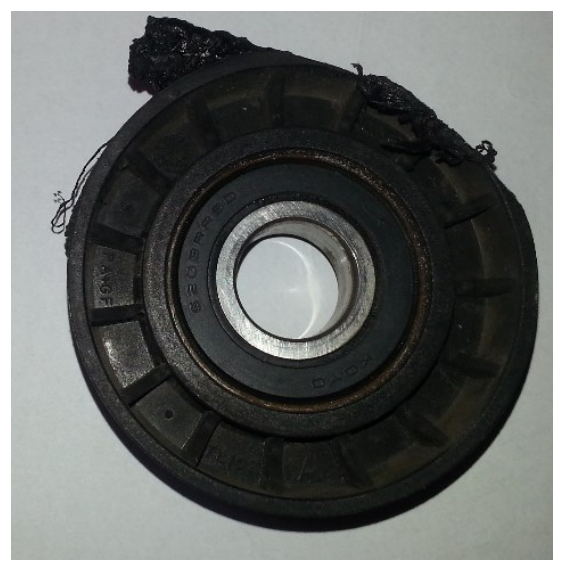

Fig. 13. The sample failure of multi-groove pulley tensioners

The most common reasons of multi-groove pulley tensioner failures (fig. 13) are:

- rusty dripstones and cracks. Rusty liquid flows between tensioner arm and base or it drips from the tensioner. Rust leaks are the symptoms of internal wear of a part. Most of these types of failure occur where the limiters and tensioner mounting screws are.

- the wear of pulley bearing. The symptom of this failure is noise, resistance while turning the tensioner manually.

- the wear of the pulley. Correctly exploited pulleys of tensioners should be smooth and without any chirps, cracks or contaminations in the grooves. The spokes on the side surfaces of (plastic) pulleys should not be cracked or broken.

- assembly misalignment of the tensioner. The reason of this failure is lack of alignment while assembling the tensioner. The direct reason of such failures may be misaligned base of the tensioner, incorrect assembly of the tensioner or corrosion.

- noise coming from the tensioner. The noise from the tensioner is most of them caused by the failure of the bearings.

- misalignment of the tensioner arm. The main reason of this failure is improper belt leading on the tensioner's pulley. The visible symptoms of this situation are shiny, smooth strands or carves in the shield or tensioner arm. This situation may be caused by an interaction between metal arm and metal shield of the spring.

- excessive vibrations of tensioner arm. Vibrations of tensioner arm are caused by its tendency to fall into constant vibrations. Such state is caused by an impropriate suppression system or lowered spring tension.

- the loss of spring properties. If there is no resistance detected while turning the tensioner, it may mean that probably the spring lost its properties. Other symptoms of this failure are belt noise resulting from slipping or torque speed drop of the propelled part.

\section{Conclusions and suggestions for designers}

In order to assure proper time of failure- less work of belt pulley it is essential to:

- while exchanging or assembling the belt to change the distance between the pulleys in order to make it easier to fit the belt and then pull it to obtain a proper slippage (assuming $1,5 \%$ tolerance of the belt total permissible lengthiness while work and $1 \%$ tolerance of the belt length),

- use only the pulleys that were manufactured in accordance with standards and catalogues of prestigious producers. In case of poly-V belt pulleys only belt sheaves should be used that consist of belts compiled especially in accordance with length tolerance, 
- check if pulley and belt grooves are clean, damage less or without any anti-corrosion substances,

- pay an extra attention to a proper assembly of a tie. The belt should be set in grooves in such way that it adjoins its all sidewall with the walls of the groove,

- not use any substances that increase the adhesiveness of belt to the pulley,

- remember that the acceptable misalignment of transmission pulley axis should not exceed $1 \mathrm{~mm}$ per $100 \mathrm{~mm}$ of axis length and the tolerance of mutual displacement of pulley grooves should not exceed $0,25 \%$ of distance between the axis, during the first hours of its work the belt stretches and then its tension should be corrected. As it results from experimental research after one hour of work under full load, the belt lengthens by about 60 $\%$ of the total acceptable lengthiness, which is $1,5 \%$ of the belt length,

- if one belt is broken in the belt transmission then all the belts should be exchanged,

- secure the transmission with a protective shield,

- use proper assembly of belt tensioner and monitor its work regularly.

\section{References}

1. F. M. Feldhaus, Maszyny w dziejach ludzkości. (PWN 1958)

2. www2.gates.com

3. M. Dudziak, Przektadnie cięgnowe. (PWN, Warszawa, 1997)

4. M. Dudziak, P. Krawiec, R. Mostowski, Pasy zespolone Poli-V. Zeszyt Specjalny Politechniki Lubelskiej, 229-234 (1995)

5. M. Dudziak, P. Krawiec, R. Mostowski, Aspekty doboru i zastosowań przekładni pasowych z pasami zespolonymi. Zeszyt Specjalny Politechniki Warszawskiej, 121-126 (1995)

6. K. Kubas, A research stand for measuring friction parameters in a belt transmission. The Archives of Automotive Engineering 75, 69-82 (2017)

7. G. Sheng, H. Lee, V. Narravula, Experimental characterization and analysis of wet belt friction and the vibro-acoustic behavior. Tribology International 44, 258-265 (2011)

8. L. Kátai, I. Szabó, Identification of V-belt power losses with temperature measurement. Journal of Mechanical Science and Technology 29, 3195-3203 (2015)

9. www.machinedesign.com/technologies/pushing-belt-drive-efficiency 